\title{
Effective methods for knowledge transfer to strengthen mental health systems in low- and middle-income countries - CORRIGENDUM
}

Jose L. Ayuso-Mateos, Maria Miret, Pilar Lopez-Garcia, Atalay Alem, Dan Chisholm, Oye Gureje, Charlotte Hanlon, Mark Jordans, Fred Kigozi, Crick Lund, Inge Petersen, Maya Semrau, Rahul Shidhaye and Graham Thornicroft

\section{Copyright and usage}

(c) The Royal College of Psychiatrists 2021. This is an Open Access article, distributed under the terms of the creative Commons Attribution-NonCommercial-NoDerivatives licence (http://creativecommons.org/licenses/by-nc-nd/4.0/), which permits noncommercial re-use, distribution, and reproduction in any medium, provided the original work is unaltered and is properly cited. The written permission of Cambridge University Press must be obtained for commercial re-use or in order to create a derivative work.

https://doi.org/10.1192/bjo.2019.50, Published online by Cambridge University Press, 06 August 2019

The above mentioned article has been updated to correct website links to additional tools and resources provided by the Emerald Project.

\section{Reference}

Ayuso-Mateos JL, Miret M, Lopez-Garcia P, Alem A, Chisholm D, Gureje O, Hanlon C, Jordans M, Kigozi F, Lund C, Petersen I, Semrau M, Shidhaye R and Thornicroft G. Effective methods for knowledge transfer to strengthen mental health systems in low- and middle-income countries. BJPsych Open. Cambridge University Press: 2019;5(5):e72. 